\title{
Fire Fighting Robot Using GSM Technology and Smart Camera
}

\author{
${ }^{1}$ M.Dheeraj Singh, ${ }^{2}$ Y.V.Adithya Kumar, ${ }^{3}$ G. Bharath Sai, ${ }^{4}$ P.Naveen \\ Department of Electronnics and Communication Engineering \\ Kalasalingam Academy of Research and Education \\ Krishnan koil, Tamilnadu, India
}

\begin{abstract}
Fire accidents have been occurring frequently in these days, with or without the intervention of human. Whatever may be the reason it is one of the reason for huge blow to the mankind. Different losses would occur in the form of property, land, humans and animals too. Nature is also losing its environmental balance. Before the fire get widespread we have to inhibit it in initial stages. With the use of current technology we have developed a robot. In our paper, we will give the information about the design and construction of it. This fire fighting robot uses GSM technology. When the Robot detects fire, it gives message to the user by the use of GSM. A wireless smart camera which is fixed to it gives the video coverage of the surroundings. By the use of DTMF concept, we can control the movement of the robot in the direction we prefer. 8051 microcontroller is the main component of the project. It only sends and receives all major signals.
\end{abstract}

Keywords:- DTMF, GSM.

\section{INTRODUCTION}

Fire Fighting is the one of the most toughest job, as the life risk for it is very high. Most of the times firemen will be affected by burns or suffocation in those places where the fire has caught. Recently, the forest fires are increasing drastically over the world. In these times we have to widespread of fire and also have to protect fire fighting men. In aspect of achieving this goal we have designed a fire fighting robot using GSM technology. This project will be an additional boost to the firemen without making risking their lives. A fire sensor will be present which detects the combustible gas and gives message to the user with the help of GSM module. ATMEGA328 microcontroller acts as a bridge between the gas sensor and GSM, and also gives the message to 8051 microcontroller which plays a pivotal role in this project. DTMF(Dual Tone Multiple Frequency usage helps in controlling of the robot. It moves in different directions with the tone produced by the remote ( which we use is a mobile phone). A wireless camera which showcases the surroundings in every possible direction is controlled by a V380 applications. With this we can listen the sound from the surroundings and also can send audio message too.

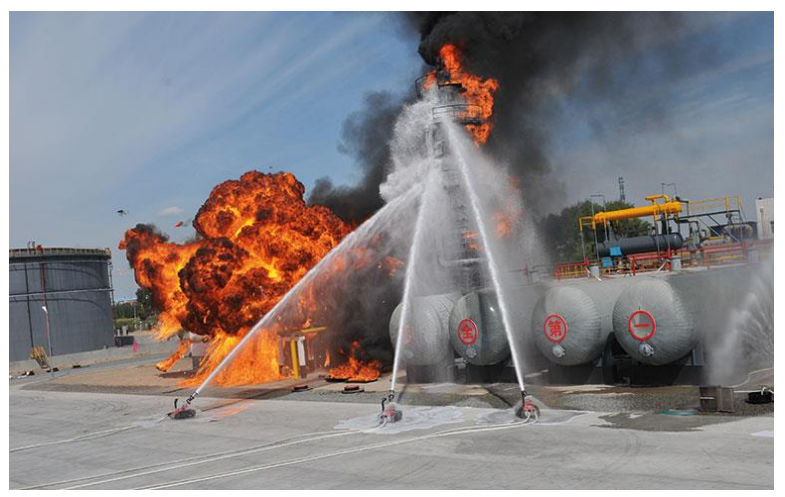

Fig 1:- Fire Fighting Robot

\section{METHODOLOGY}

The main theme of the project is to detect fire and extinguishing it. This whole project is divided into three categories as detection, processing of signal and extinguishing of fire. In the process of signal detection, a fire sensor will be there which detects combustible gas. After switching on the project, it takes some subtle time to establish. This time is called pre hitting time which is of 40 seconds.

This fire detected signal will be sent to the user in the form of a message which is performes by the use of GSM. In addition to it, we have a buzzer, for the detection of the fire. The second category of the project is to process the signal. There are total three motors in this robot. Two motors will be for the motion of the robot. Remaining one is used for splashing of the water over the fire. For this purpose we are using the motor of car wind screen. Relays are to be used along with the motors. Totally we use 5 relays in this project. One relay is for the pump motor, remaining four relays are used for the motors which are used for motion purpose.

\begin{tabular}{|c|c|}
\hline Number & Direction \\
\hline 1 & Forward \\
\hline 2 & Backward \\
\hline 3 & Leftward \\
\hline 4 & Rightward \\
\hline 5 & Stop \\
\hline 6 & Pump on \\
\hline 7 & Pump off \\
\hline
\end{tabular}

Table 1 
All these relays are in the same type of alignment. These relays are also consists of two transistors and a diode. These transistors would be used for the amplification purpose and the diode is used as for back EMF. 8051 microcontroller plays important role. It sends the information to these motors via relay. For driving this circuit there is power supply which consists of voltage controller, 4 diodes and a capacitor. The robot moves in different directions basing on the controls given to it.

These controls are given by DTMF IC. DTMF(Dual Tone Multiple Frequency). For very number we press ,there will be certain set of standard tone. So, it will move in the direction programmed in it for the certain number. The two types in it are, wired and wireless. There is a wire connected to the IC and mobile phone. For the wireless purpose we use DTMF application. We can also control this robot from far distant places by calling to the wired phone using auto call connect option. So, by typing in one place, this robot can move in another place which is of larger distances.

The fire detected signal before going to the GSM, it will process through ATMEGA 328 microcontroller. This microcontroller sends signals of information to the GSM and also the 8051 microcontroller. After recieving the signal from DTMF, it will be directed into 8051 which finally sends the information to demotors. Motors will perform its functions after they received. A wireless smart camera is used for capturing the surroundings. It covers in all directions. It is controlled by V380 application. With this we can listen the surrounding sounds and also can send our audio too.

\section{PROJECT HARDWARE KIT}

This is our project hardware kit which is includes smart camera and dtmf technology(dual tone multi frequency) and a gas sensor todetect fuel gas and with the use of gsm module, it sents message to the user.

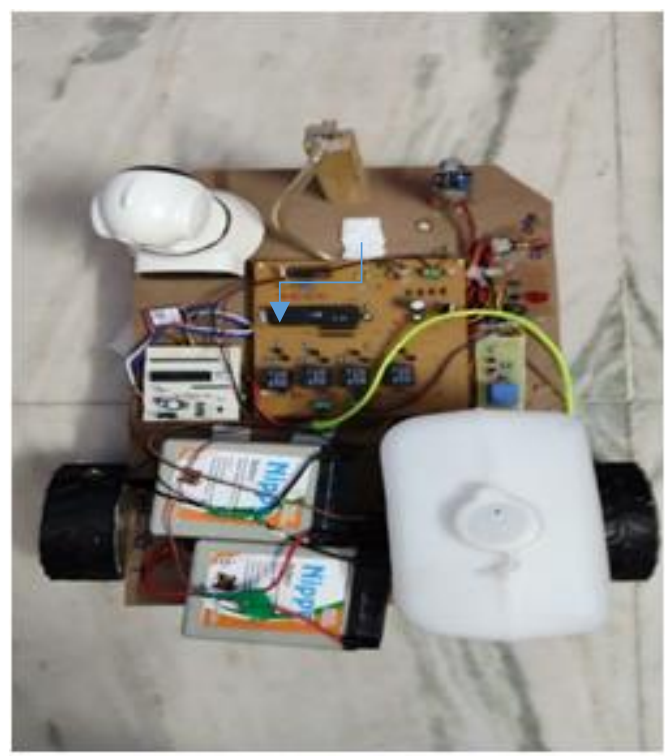

Fig 2:- Project Hardware

\section{BLOCK DIAGRAM AND FLOW CHART}

\section{A. Block Diagram:}

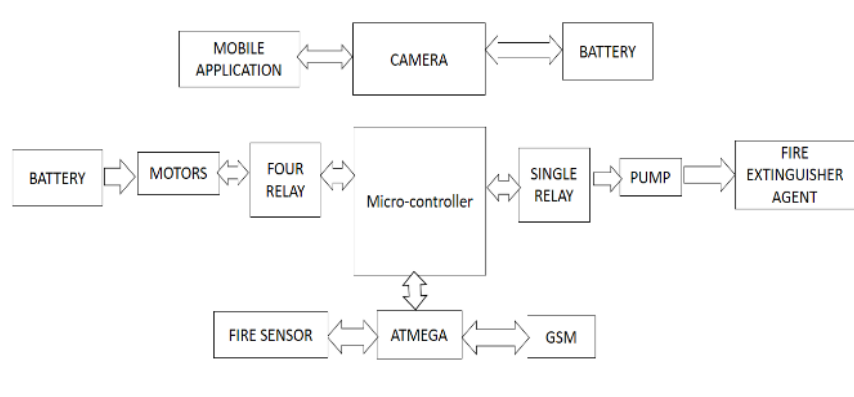

Fig 3

\section{B. Flowchart:}

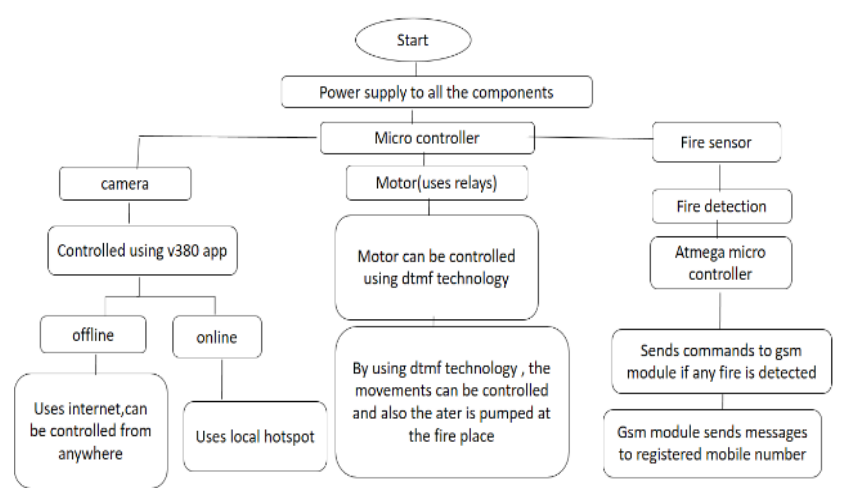

Fig 4

\section{COMPONENTS DESCRIBTION}

\section{A. 8051 microcontroller}

It's a small and less cost microcontroller. It's version is of 8 bits, with inbuild 40 pins DIP (Dual-In Line) package.ROM storage is $4 \mathrm{~kb}$ and the RAM storage is 128 bytes. It has two 16 bit timers and has 4 parallel 8 bit ports which can both programmable and addressable. The on chip crystal oscillator, which is integrated within the microcontroller is having max frequency of $12 \mathrm{Mhz}$. It has data bus of 8 bit and address bus of 16 bit and all bus control signals.

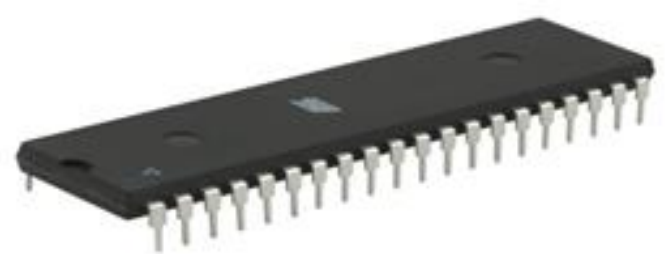

Fig 5:- 8051 Micro Controller 


\section{B. $G S M$}

GSM stands for Global System for Mobile Communication. It is used for transmitting mobile voice and data services which will operate at different frequency bands. It uses Time Division Multiple Access (TDMA) used for communicate the information. In this project we use SIM 800. It is a quad-band GSM/GPRS module that works on $850 \mathrm{MHz}$ GSM, $900 \mathrm{MHz}$ EGSM, $1800 \mathrm{MHz}$ DCS and $1900 \mathrm{MHz}$ PCS. It also features GPRS multi slot Class 12/Class10(optional) and supports CS-1,CS-2,CS-3 and CS-4 GPRS coding schemes.

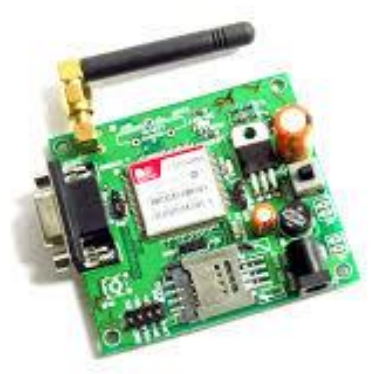

Fig 6:- GSM Module

\section{Relay}

Relays are the switches which closes and open the circuits either by electromechanically or electronically. it's a tool that opens or closes the contacts to cause the operations of other electric control. It gives the commands to the breaker, when it detects the undesirable condition under an assigned area, it disconnects the affected area through ON and OFF.

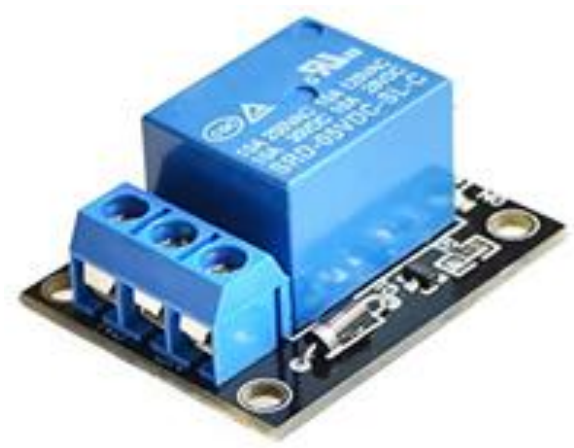

Fig 7:- Relay

Normally it consists of electromagnet, mechanically movable contact, switching points and spring.

\section{DTMF IC}

Dual Tone Multi Frequency in short DTMF. This technology provides Ultimate Solutions for the phonephone Industries which is employed to modify two lines automatically. During the yesteryears, these telephone systems were operated manually in a telephone exchange room. Operator plays a key role, takes instructions from the caller and connects to their destination lines. An IC has been developed to use this technology.

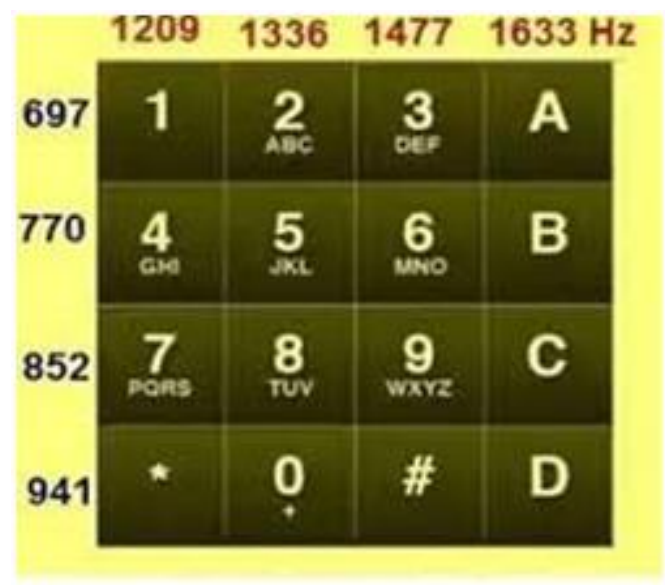

Fig 8:- DTMF Technology

\section{E. AT Mega $328 P$ IC:}

It is a single chip microcontroller belongs to Atmel, in the mega AVR family. AVR is a short for Automatic Voltage Regulator. This microcontroller is of/ an 8 bit microcontroller and $32 \mathrm{k}$ of flash memory, $1 \mathrm{k}$ of EEPROM and $2 \mathrm{k}$ of internal SRAM. It has $28 / 32$ pins. Its operating frequency is of maximum $20 \mathrm{MHz}$.

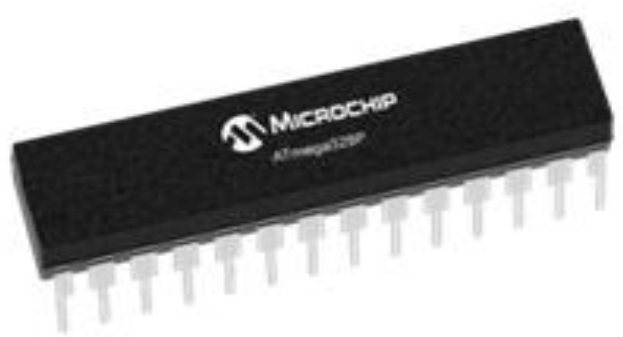

Fig 9:- ATMEG 328P IC

\section{F. Wireless Camera:}

These are used to cover the video footage of the surroundings without wires. It works by transmitting the camera's video through a radio (RF) transmitter. A Receiver receives this video with a built in storage device or through cloud storage. By the help of receiver, we have an access to the images/video clips with a link. It needs a lot of power to run constantly. The main advantage is we can view it through the device which we prefer whether it is monitor or from a smart phone.

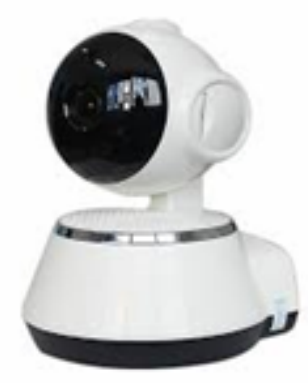

Fig 10:- Wireless Smart Camera

It is powered in two ways. One is powered by mains and the other iswith battery power. In this project we used is battery powered cameras. 


\section{G. DC Motor:}

DC means Direct Current. It is named as by the connection of the field winding the armature. It converts the electrical power to mechanical power. Main working principle of the motor is based on the principle of current carrying conductor is placed on the magnetic field and a mechanical force experience by it which causes it to rotate with its respect to original position. Electric DC motor has two parts. One part is called rotor and the other part is called stator. Rotor rotates with respect to the stator.

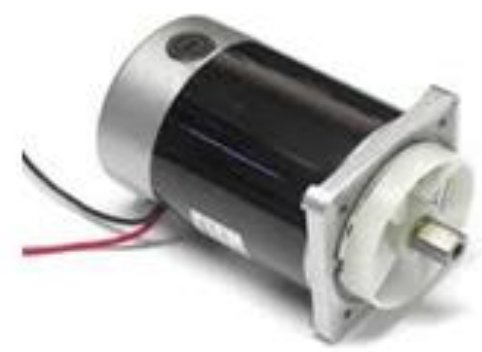

Fig 11:- DC Motor

\section{H. GAS Sensor:}

Fire Sensor is a device which detects the fire. Mainly it detects the temperature and some other features related to it. Categories in it are flame detection, gas detection and smoke detection. In this project we are using gas detection sensor. Mainly we use this sensor in household purposes. In houses LPG gas leak likewise many things may happen which are causes for the fire outbreak. In this project we use Gas sensor (MQ 2). This is used in detecting H2, LPG, Methane, CO, Alcohol, Smoke etc.

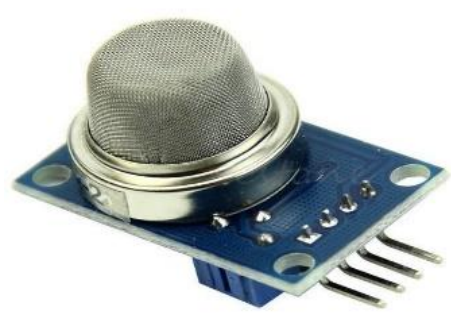

Fig 12:- Gas Sensor

\section{OBJECTIVES}

Death rate belongs to fire accidents and forest fire has been increased. Initially this fire starts from a smaller area. If we can find out the starting place before the fire gets widespread, we can inhibit it. In this project the main objective is to stop the spread of this fire. For that we have to detect the fire in its initial stage. Fire sensor which is placed in the project will determine the fire. Surroundings of the robot should be tracked for avoiding collisions. A wireless camera which is fixed to it covers the surroundings. Robot motion plays a major role in the project. Locomotion of the project is controlled by a remote which is done by DTMF IC. The detected fire signal, should reach the end user is also an objective of this paper. Reaching of this signal to end user is achieved by using
GSM. Coordination of all the equipped parts is also an important factor. All the components are connected to 8051 microcontroller and it acts as a heart of the project. All the commands related to fire detection signals are given to that microcontroller it operates the remaining components of the robot in moving and pumping of the water.

\section{CONCLUSION AND FUTURE WORK}

The fire fighting robot has been build successfully. All its moving actions forward, backward and sideward are also being performed. By the water pump system arranged in it can splash the water on the fire. This robot can be operated from shorter distance to larger distance. The smart camera which is fixed to this robot can monitor the surroundings. This project helps in further development in fire fighting. It backs the firemen while doing their work. This paper also helps in understanding the concepts in fighting with the fire and tells the importance of this field. By making advancements to this project without the intervention of the human, the robot has to cease the fire which is our future scope. Finally this project has achieved its aim and objective.

\section{REFERENCES}

[1]. E. Krasnov and D. Bagaev, "Conceptual analysis of firefighting robots' control systems," 2012 IV International Conference "Problems of Cybernetics and Informatics" (PCI), Baku, 2012, pp. 1-3.

[2]. K. L. Su, "Automatic Fire Detection System Using Adaptive Fusion Algorithm for Fire Fighting Robot," 2006 IEEE International Conference on Systems, Man and Cybernetics, Taipei, 2006, pp. 966- 971.

[3]. H. Amano, "Present status and problems of firefighting robots," Proceedings of the $41^{\text {st }}$ SICE Annual Conference. SICE 2002., 2002, pp. 880-885 vol.2.

[4]. A. Bradshaw, "The UK Security and Fire Fighting Advanced Robot project," IEE Colloquium on Advanced Robotic Initiatives in the UK, London, 1991, pp. 1/1-1/4.

[5]. T. L. Chien, H. Guo, K. L. Su and S. V. Shiau, "Develop a Multiple Interface Based Fire Fighting Robot," 2007 IEEE International Conference on Mechatronics, Kumamoto, 2007, pp. 1-6.

[6]. T. Rakib and M. A. R. Sarkar, "Design and fabrication of an autonomous firefighting robot with multisensor fire detection using PID controller," 2016 5th International Conference on Informatics, Electronics and Vision (ICIEV), Dhaka, Bangladesh, 2016, pp. 909- 914.

[7]. J. H. Hwang, S. Jun, S. H. Kim, D. Cha, K. Jeon and J. Lee, "Novel fire detection device for robotic fire fighting," ICCAS 2010, Gyeonggido, 2010, pp. 96100 .

[8]. L. Celentano, B. Siciliano and L. Villani, "A robotic system for firefighting in tunnels," IEEE International Safety, Security and Rescue Rototics, Workshop, 2005., Kobe, 2005, pp. 253-258. 
[9]. D. J. Pack, R. Avanzato, D. J. Ahlgren and I. M. Verner, "Firefighting mobile robotics and interdisciplinary design-comparative perspectives," in IEEE Transactions on Education, vol. 47, no. 3, pp. 369-376, Aug. 2004.

[10]. M. Sato, H. Torikai and Y. Iwatani, "Flame extinguishment by a prototype of an aerial extinguisher with an inert gas capsule," The SICE Annual Conference 2013, Nagoya, Japan, 2013, pp. 2051-2056.

[11]. Tong feng, $\mathrm{Xu}$ Lufeng and Tong Daoling, "An ultrasonic obstacle avoidance system for firefighting robot," Proceedings of the 4th World Congress on Intelligent Control and Automation (Cat. No.02EX527), 2002, pp. 1219-1222 vol.2.

[12]. M. Li-xin, S. Dao-nian, C. Min-xuan, and W. Xiaoqin, "Application of Intelligent PID Control for Robot", IEEE Conference on Cybernetics and Intelligent Systems, pp. 455-458, 21-24 Sept. 2008.

[13]. Automated Fire Fighting System with Smoke and Temperature Detection Mohammad Jane Alam Khan, Muhammed Rifat Imam ,Jashim Uddin, M. A. Rashid Department of Mechanical Engineering, Bangladesh University of Engineering and Technology Dhaka1000, Bangladesh

[14]. Hardware based Automatic Fire Extinguisher Robot B. Swetha Sampath Department of Electronics and Communication Engineering, JNT University, Hyderabad.

[15]. Autonomous Fire Extinguishing System A. Rehman, N. Masood, S. Arif, U. Shahbaz, National University of Sciences \& Technology, Islamabad,Pakistan F. Sarwar, K. Maqsood, M. Imran, \& M. Pasha Department of Mechatronics Engineering, Air University, Islamabad, Pakistan

[16]. Autonomous Fire Fighting Mobile Platform. Tehnam khoon,Patrick Sebastian, Abu bakar Sayuti Sayan Universiti Technologi PETRONAS, Bandar Seri Iskandar, Malaysia. 